\title{
Entomopathogenic Nematodes against Insect Pests of Rice
}

\section{Gitanjali Devi}

Department of Nematology, Assam Agricultural University, Jorhat-13, Assam, India

\begin{abstract}
Rice is one of the important staple crop in the world. Rice pests cause yield reduction as well as value of the crop. A number of insect pests that attack rice plants account for yield losses. In the rice agro ecosystems, many types of entomopathogens such as nematodes, fungi, bacteria, and viruses can reduce pest population. More emphasis should be placed on using an IPM approach where biological control with entomopathogens is also one of the main components. Entomopathogenic nematodes (EPN) as a safe alternative to the use of insecticides against insect pests in IPM of rice.
\end{abstract}

Keywords-Rice, Insect pests, Biological control, Entomopathogenic Nematodes.

\section{INTRODUCTION}

Rice being a tropical plant is also adaptable to a broad range of climatic, edaphic and cultural conditions. It provides $20 \%$ of the per capita energy and $15 \%$ of the per capita protein for humans worldwide (Mikkelsen and Datta, 1991). Rice is grown in more than a hundred countries, with a total harvested area of approximately 158 million hectares, producing more than 700 million tons annually. Nearly 640 million tons of rice is grown in Asia representing $90 \%$ of global production (Way and Bowling, 1991). Rice production should be increased to supply a rapidly expanding population; however, it has been hindered by a number of diseases and insect pests. Moreover, rapid changes in rice production technologies have created greater frequencies of pest epidemics (Reissig et al., 1986).

\section{INSECT PESTS STATUS}

A number of insect pests that attack rice plants account for yield losses of $24 \%$ worldwide. Insect pest cause at least 20 per cent field losses in rice in India (Pathak et al., 1982). More than 70 species of insect pests are known to feed on rice, and at least 20 of them can seriously affect rice production. A variety of factors can contribute to pest outbreaks, including climatic factors, improper irrigation, high rates of nitrogen fertilizer application, overuse of insecticide. Insect pests attack all parts of the rice plant at all growth stages and some serve as vectors of viruses that adversely affect the plant.

Brown planthopper (Nilaparvata lugens) and white-backed planthopper (Sogatella furcifera) are serious pests of rice. They occur in tropical to temperate areas with high reproductive potential and can cause extensive damage through their feeding activity and transmission of viral diseases like rice grassy stunt and ragged stunt. Nymphs and adults suck sap from the base of plants, just above the waterline. In heavy infestation, these planthoppers can cause hopperburn resulting in browning and wilting of some or all tillers in a hill (Kuno, 1968). Most of the rice varieties are susceptible to this pest.

The rice stem borer, Chilo suppressalis has been one of the most important pests. It can cause significant damage by reducing tiller number. Females are capable of laying eggs in masses near the base of rice leaves or leaf sheaths. The larvae penetrate tillers and feed on the inner surface of the stem walls, interrupting the movement of water and nutrients. The central leaves of damaged tillers of young plants turn brown (called dead hearts).If the damage occurs after formation of spikelets, panicles turn white (called whiteheads) and no grain filling occurs. The plant often dies and the larvae move to another stem.

Rice water weevil (Lissorhoptrus oryzophilus) the larvae cause much more damage, as they feed on roots and prune 
them, than the adult weevils feeding on leaves. The yield loss could reach up to $70-80 \%$ with heavy infestation.

\section{MANAGEMENT OF INSECT PESTS}

Control of insect pests has primarily depended on the application of chemical insecticides. Chemical insecticides are expensive, besides other disadvantages, including secondary pest resurgence, insecticide resistance, environmental pollution, and impact on nontarget organisms. The utilization of pathogenic microorganisms holds a high possibility for the suppression of rice insect pests (Otake, 1979; Chatterjee et al. 1983; Pathak et al., 1982; Heong, 1983). In recent years more emphasis has been placed on using an IPM approach where biological control is also one of the main components. In the rice agro ecosystems, many types of entomopathogens such as nematodes, fungi, bacteria, and viruses can reduce pest population.

Nematodes have been found associated with most of the insect orders. There are more than 3100 natural associations between insects and nematodes involving 11 orders of nematodes and 23 orders of insects. The association may range from a phoretic relationship to obligate entomoparasitism leading to host death, sterility, reduced fecundity or delayed development. Some that are associated with one host and its special ecology are highly specialized and difficult to propagate on an artificial medium while other less specialized forms have wide host range, can be mass produced on artificial media, and are currently used for control of agricultural pests. Entomopathogenic nematodes (EPN) as a safe alternative to the use of insecticides in IPM of different crops, including rice, have gained worldwide attention (Table 1).

\section{MODE OF ACTION}

Mermithids are a large group of obligate entomopathogenic nematodes that are considered important regulators for some insect populations (Kaiser,1991). Mermithid parasitism results in nutritional depletion, retarded growth, organ disruption, reduced fecundity or sterility and death. The newly hatched second stage mermithid is the infective stage (pre-parasite).Once the mermithid contacts the plant hopper nymph, it uses its stylet to penetrate through the cuticle into the host hemocoel to initiate the parasitic phase. The $3^{\text {rd }}$ and $4^{\text {th }}$ stage juveniles occur in the hemocoel. Two to three weeks after parasitization, the $4^{\text {th }}$ stage juvenile (post parasite) exits its adult host by boring through the thin intersegmental area of the abdominal segment, causing death of the host. After emergence, the postparasite burrows into the soil, molts, and overwinters as an adult (Sutanov et al., 1990; Vandergast and Roderick,2003; Kamminga et al.2012).

Steinernematidae and Heterorhabditidae have attracted most attention as they contain the EPNs Steinernema and Heterorhabditis. The nematodes musualistically associated with insect-pathogenic bacteria. The bacteria Xenorhabdus and Photorhabdus (Family: Enterobacteriaceae) are symbiotically associated with Steinernema spp. and Heterorhabditis spp. respectively. These bacteria are ecologically obligate to EPNs, with specific mechanisms of pathogenicity and their existence in free form in nature is believed to last a very short while due to photo and thermo sensitivity. These nematode bacterium associations meet many criteria for augmentative control of insect pests through inundative releases including: broad host range; ability to kill hosts rapidly : a durable infective stage capable of storage; distribution; and persistence; available mass inexpensive mss production technologies; no evidence of insect immunity; safety to plants and vertebrates; and application with existing spray equipment. The third stage dauer juvenile (DJ) occurs free in the soil and its role is to seek out and infect an insect larva. These free-living, nonfeeding juveniles and developmentally arrested third stage juvenile ranging in length from $0.4 \mathrm{~mm}$ to $1.1 \mathrm{~mm}$. Steinernema gains entry to the insect larva through natural openings (mouth, anus and spiracles). In addition to these modes of entry, Heterorhabditis also gains entry by abrading the intersegmental membranes of the insect. Once in the haemocoel of the insect the DJ releases cells of a symbiont bacterium that it carries in its intestine. The insect haemolymph provides rich medium for the bacterial cells and these begin to grow, release toxins and exoenzymes and kill the insect. The insect dies rapidly, usually within 24-48 h. Generally life-cycle of entomopathogenic nematodes is completed within 12-15 days at room temperature. Depending on the availability of food resource, both heterorhabditis and steinernematids generally complete $2-3$ generations within insect cadaver and emerge as infective juveniles to seek new hosts.

\section{PARASITISM / BIOEFFICACY}

Imamura (1932) reported that Mermithidae were parasitic on Chilo simplex. Grewal et al., (2006) recorded it in Asia. Pena \& Shepared (1985) recorded 50\% parasitisation of BHP by Hexamermis sp. in Phillippines. Heong (1983) reported that an entomopathogenic nematode Amphimermis unka caused 
high mortality of hoppers pest in China. Natural incidence of parasitism by Hexamermis sp. on BPH was first reported in south India by Manjunath (1978) and in eastern india by Satpathi (1999). Ramani, (2003) also reported that Hexamermis sp. was most important nymphal /adult parasitoid from India. Satpathi et al., (2008) studied in detail about the factor affecting abundance of parasitic nematode Hexamermis sp. in eastern India. Jayanthi et al., (1987) recorded parasitism (12\%) by mermithids in rice planthopper. Rhabditis sp. (Oscheius sp.) was found to be effective against egg mass and neonate larvae of Scirpophaga incertulas (Padmakumari et al.,2007;2008).

Agamermis species infecting insects have been reported in North America (Cobb et al.,1923; Christie,1936), Asia (Kaburaki and Imamura 1932; Choo et al.1995), Australia (Baker and Poinar,1995), Africa (Igbinosa,1988), China (Bao et al.,1992) and Europe (Rubtsov,1969;1977). Agamermis unka is the most important and common natural enemy in temperate regions. Agamermis species live in the soil and infect hosts from the soil directly or after short migration up to plant stem (Nickle, 1981; Choo et al., 1995). Agamermis unka was first collected by Esaki and Hasimoto,1931 from BPH and WBPH at Oita, Japan and described as a new species (Kaburaki and Imamura,1932; Fuse and Sato,1968). Esaki and Hasimoto (1931) found that $>40 \% \mathrm{BPH}$ and $>70 \%$ of WBPH populations were parasitized. Mermithid nematodes have received attention as possible biocontrol agents of brown planthopper (BPH). A number of studies were initiated to determine its role as a mortality factor in plant hopper population. Agamermis parasitism castrates the reproductive organs of BPH and WBPH. In Philippines, 50\% parasitism of $\mathrm{BPH}$ by an unidentified mermithid was recorded during the wet season (Otake, 1979), but parasitism was low throughout the year and its impact as a natural control agent of BPH was negligible. Parasitism of the host usually occur at the lower part of the rice stem where most planthoppers are found (Cho et al.,2002; Choo and Kaya, 1990;1991;1993). In Korea, Agamermis unka is a major natural enemy of the brown planthopper, Nilaparvata lugens(Stal) (Hemiptera: Delphacidae), and the whitebacked leafhopper, Sogatella furcifera (Horvath) (Hemiptera: Delphacidae), and has been widely studied regarding future inoculative releases and conservation approaches to mange populations in rice (Choo and Kaya,1994).When the pre parasites of $A$. unka were released at a mermithid to BPH of 10:1, parasitism of BPHs ranged from 33 to $63 \%$ (Choo et al.,1995). Agamermis can be redistributed by artificial releases. Agamermis unka is an important mortality factor in planthopper populations in Korea. It kills the adult and reduces the fecundity of the females. Males of BPH and WBPH are susceptible to parasitism by A.unka (Kuno,1968). As egg production and hatchability of Agamermis are high, inoculative releases into areas where the mermithid population is low or nonexistent appear feasible. To affect plant hopper populations; the mermithid must parasitize a high number of progeny of the migrating population. Both the short-winged (brachypterous form) and the long-winged (macropterous form) adults are susceptible to mermithid parasitism, but the brachypterous form (57\%) had higher parasitism than the macropterous form $(8 \%)$ (Choo et $a l ., 1989)$.The brachypterous form is usually found lower on the rice plant where the mermithid is more likely to encounter it. A. unka would be most effective when the migrating adult insects produce few progeny and the parasitic stage of the mermithid occurs in high numbers. About $30 \%$ of the natural controls of brown plant hopper in eastern India are due to parasitic nematode (Satpathi et al., 2008). A control strategy would be to reduce the number of progeny produced by migrating adults. This can be accomplished through an integrated manner with chemical or biological insecticides, resistant cultivars, cultural methods, or a combination of these control tactics. Before an integrated pest management system can be incorporated in the field, further studies on the biology of the nematode and its compatibility with current control tactics are needed. Rice water weevil adults can be parasitized by mermithid, as has been reported in native regions (Bunyarat et al., 1977).These parasites may reduce fecundity and cause high mortality in infected adults. Rice blue beetle (Leptispa pygmaea) was reported to be parasitized by Hexamermis (Patel and Shah,1988). This mermithid is already established in the rice fields in Korea, appears to be compatible with some chemical pesticides, and reduces the fecundity of its host (Choo et al., 1998). Cultural practices such as tilling and irrigation can increase the performance of A.unka. We have to enhance the effectiveness of the naturally occurring mermithid into an IPM program to reduce BPH population. Genus identification through molecular technique can help predict and infer mermithid biology, which can ultimately assist in rearing protocols, if mermithids are to be used for future research and incorporation into current management protocols.

In India, efforts were made during 1970s to study the effectiveness of exotic EPNs, S.carpocapsae (DD-136) 
against insect pests of rice (Rao et al., 1968). However, the nematode was not able to become established in field trials. S. carpocapsae (DD-136) causing up to $98 \%$ mortality and fast multiplication on $5^{\text {th }}$ instar larvae of Cnaphalocrocis medinalis (Srinivas and Prasad,1991). Choo et al. (1989) reported that Steinernema carpocapsae and Heterorhabditis bacteriophora are very effective against the rice yellow stem borer, Scirpophaga incertulas causing mortality and proved EPN as a potential biocontrol agent in rice eco system. $S$. carpocapsae or H. bacteriophora were sprayed at the rates of 250, 500, 1000 or 2000 IJs for S. carpocapsae and 100, 200, 400 or $800 \mathrm{IJs}$ for $H$. bacteriophora. Seven days after treatment, showed that both nematodes were effective causing more than $91 \%$ mortality. On the other hand, mortality was $42.6 \%$ and $63.1 \%$ when stems were dipped into a nematode suspension at the rate of 100 or $200 \mathrm{IJs}$ of $H$. bacteriophora. Because the moist habitat of rice stems were favorable to nematode survival and searching abilities, entomopathogenic nematode, were confirmed to be a potential biological control agents against rice stem borers (Choo et al., 1991). Prasad et al., (2006) reported that H.indica caused $100 \%$ mortality of rice leaf folder, Cnaphalocrocos medinalis within 18 to 20 hours of exposure. Padmakumari et al. (2008) reported that lethal time of $19.8 \mathrm{~h}$ was recorded by $H$. indica and $37.8 \mathrm{~h}$ by $S$. asiaticum on $C$. medinalis in a bioassay study. Combined inoculation of $H$. indica and $S$. asiaticum each at $75 \mathrm{IJ} /$ /larva resulted in faster larval mortality on $C$. medinalis $(24.6 \mathrm{~h})$. The percent larval mortality caused by $H$. indica alone was resulted significantly more $(60 \%)$ than $S$. asiaticum $(40 \%)$ on C. medinalis. Progeny produced by $H$ indica and $S$. asiaticum 4843 and $4330 \mathrm{IJ} /$ larva respectively on $C$. medinalis larva (Sankar et al., 2009). Heterorhabditis indica caused 66.67 to 91.67 per cent mortality at concentrations of 5IJs to 9IJs in the grubs of L. pygmaea (Karthikeyan, and Jacob, 2009). Spraying of H.indica @ 3000 IJs /ml was effective in reducing the white ear incidence, @ $2500 \mathrm{IJs} / \mathrm{ml}$ was also equally effective in reducing the gall midge incidence at $25 \mathrm{DAT}, H$. indica applied @ $3000 \mathrm{IJs} / \mathrm{ml}$ was the superior treatment at 25 days after transplanting while at the later stage (55 days after transplanting), a lower dose @ $2500 \mathrm{IJs} / \mathrm{ml}$ was found to be sufficient to bring about significant control of leaffolder (Karthikeyan and Jacob,2010). Among the three entomopathogenic nematodes evaluated for their biological control, maximum reduction of BPH was observed with Steinernema glaseri followed by Metarhabditis amsactae isolate Drr-Ma2 (Annon.2015).Rice stem borer (Chilo suppressalis) was reported to managed by
S.carpocapsae Pocheon strain, S.carpocapsae Iksan strain, S.monticolum Hwasun strain, H.megidis Hwasun strain in Korea (Jung et al.,2018). Efficacy of EPNs was evaluated was evaluated against the African white rice stem borer, Maliarpha separatella. Significant virulence was obtained with all the nematodes species at $200 \mathrm{IJs}$ after 48 hours of exposure in the following order H.indica $>$ Ex Nakuru (local isolate) > S.carpocapsae > Ex Mombosa (local isolate) > S.karii (Kega et al.,2013;2020). Steinernema carpocapsae was found to cause mortality against rice water weevil, Lissorhoptrus oryzophilus under laboratory setting but failed to work in the field in Japan (Nagata,1987).In Cuba, there was success using Steinernema spp. against the rice water weevil with up to $80 \%$ control in field trials(Carbonell, 1983; Meneses, 1983).In California, research with both S.carpocapsae and Heterorhabditis spp. found that nematodes provided control of rice water weevil larvae when applied to drained soil that was reflooded $8 \mathrm{~d}$ later (Grigarick and Oraze,1990).In China, the Otio strain of S. feltiae was found to cause high mortality for larvae (Sun et al.,2006) and mortality rate was affected by time and dose. Efficacy of S.feltiae, S. carpocapsae A24 strain, S.glaseri NC 34 strain, H.bacteriophora and H.zealandica have also been detected in adult weevils (Kisimoto et al.,1987). Mortality of $82.5 \%$ and $97.5 \%$ was observed in adults of $L$. oryzophilus treated with S.feltiae and H.bacteriophora, respectively, at $10 \mathrm{~d}$ after incubation with nematodes (Li et al.,2007). However, the widespread application or adoption of nematodes against rice water weevil in Asia or North America has not been possible for economic reasons (Choo and Rice, 2007).

\section{CONCLUSION}

Understanding the ecological and behavioral relationships between the nematode and insects could result in proper use of compatible insecticides or other biological control agents in providing an integrated approach to insect management. In vivo production of mermithid has been accomplished with the mermithids from the banded cucumber beetle (Creighton and Fassuliotis, 1982) and from mosquitoes (Peterson, 1984). Similarly, if BPH can be mass produced easily, in vivo production of the mermithid may be used to augment natural population. In addition to production, methods to store the eggs and adults and timing of introduction into BPH populations need to developed. Using the conservation of naturally-occurring population of mermithid, there is a need to implement an effective IPM programme. By understanding the biology and ecology of these 
entomopathogens, we may be able to use them effectively in the integrated pest management of rice through augmentation or inundative release. The microclimate of rice culture with high humidity and moderate temperature is also conductive for the survival, movement, tracking and invasion of the host by EPN and their establishment as a bio-control agent. However, there is a need for development of suitable delivery mechanisms including formulation technology for field application of this EPN. Studies are required to evaluate their bioefficacy against other rice pests as well.

\section{REFERENCES}

[1] Acharjee P, Satpathi CR,Modak MK.2020.Long term studies on the role of parasitic nematode Hexamermis sp. in controlling brown planthopper in farmer's rice field of West Bengal, India. International Journal of Current Research and Review.12 (3). DOI: http: //dx. doi. Org /10. 31782 / IJCRR. 2020.12032 .

[2] Anonymous. 2015. ICAR-IIRR Annual Report, Hyderabad, India.

[3] Baker GL and Poinar,GO.Jr. 1995. Agamermis catadecaudata n.sp.(Nematoda: Mermithidae), a parasitoid of Orthoptera in South eastern Australia. Fundamental and Applied Nematology.18: 139-148.

[4] Bao XC, Lou QG, Luo DM.(1992). A new species of Agamermis from China (Nematoda: Mermithidae). Acta Zootaxon Sinica 17: 20-25.

[5] Bunyarat M. Tugwell P. Riggs R.D.1977.Seasonal incidence and effect of a mermithid nematode parasite on the mortality and egg production of the rice water weevil Lissorhoptrus oryzophilus. Journal of Economic Entomology 6: 712-714.

[6] Carbonell R.M. 1983. Pathogens and nematodes for control of rice water weevil in Cuba. International Rice Research Newsletter. 8: 16-17.

[7] Chatterjee, P.B., Sen, S.C., Sarkar, D. and Hikimindran.1983. On the implementation of IPM in rice. Pest Management in Rice, TNAU, Coimbatore. pp. 270-279.

[8] Cho SR, Lee DW, Choo HY, Kim HH. 2002. Distribution of Agamermis unka (Nematoda: Mermithidae), a mermithid parasite of brown planthopper (Nilaparvata lugens) in Korean rice paddies. Korean Journal of Applied Entomology.41:129136.

[9] Choo HY, Kaya HK, Kim JB, Park YD. 1991. Evaluation of entomopathogenic nematodes, Steinernema carpocapsae (Steinernematidae) and Heterorhabditis bacteriophora (Heterorhabditidae) against rice stem borer, Chilo suppressalis (Walker) (Lepidoptera: Pyralidae). Korean Journal of Applied Entomology. 30:50-53.

[10] Choo HY, Kaya HK, Lee SM, Lee YI, Choo DJ.1987. Detection and identification of biological control agents from planthoppers and leafhoppers. II. Distribution of nematode parasite of brown plant hopper in the soil, with notes on bionomics. Journal of the Institute of Agricultural Research Utilization, Gyeongsang National University 21:81-85.

[11] Choo HY, Kaya HK.,Kim JB.1989. Agamermis unka (Mermithidae) parasitism of Nilaparvata lugens in rice fields in Korea. Journal of Nematology. 21:254-259.

[12] Choo HY, Kaya HK.1990. Parasitism of brown plant hopper and white backed plant hopper by Agamermis unka in Korea. Journal of Nematology. 22 (4): 513-517.

[13] Choo HY, Kaya HK.1994. Biological control of the brown planthopper by a mermithid nematode. Korean J Appl. Entomol. 33:207-215.

[14] Choo HY, Kim HH, Kaya HK.1998.Effects of selected chemical pesticides on Agamermis unka (Nematoda: Mermithidae), a parasite of the brown plant hopper, Nilaparvata lugens. Biocontrol Science and Technology. 8(3):413-427.

[15] Choo HY,Kaya HK,Kim HH.1995. Biological studies on Agamermis unka (Nematoda: Mermithidae), a parasite of the brown planthopper Nilaparvarta lugens. Biocontrol Science and Technology. 5: 209-223.

[16] Choo HY,Kaya HK.1993.Parasitism of the brown planthopper by the mermithid nematode Agamermis in rice. In: Nematodes and the Biological control of insect pests. R.Bedding, R Akhurst, H.Kaya (Eds.). pp.21-26. CSIRO, East Melbourne, Australia.

[17] Choo HY.1991.Ecological study of Agamermis unka, a nematode parasite of brown planthopper, Nilaparvata lugens (Homoptera: Delphacidae). Res. Rept. Rural Development Agency 33:185-191.

[18] Choo H.Y. Rice W.C. 2007. Evaluation of microbial agents against rice pests In. Lacey L.A. Kaya H.K. Field manual of techniques in invertebrate pathology: application and evaluation of pathogens for control of insects and other pests. 2nd ed. Springer, -loc Dordrecht, The Netherlands.

[19] Choo,HY,Lee SM,Chung BK,Park YD,Kim HH.1995.Pathogenicity of Korean entomopathogenic nematodes (Steinernematidae and Heterorhabditidae) against local agricultural and forest insect pests. Korean Journal of Applied Entomology. 34:314-320.

[20] Christie,JR.1936. Life history of Agamermis decaudata, a nematode parasite of grasshoppers and other insects. Journal of Agricultural Research.52: 161-198.

[21] Cobb NA,Steiner G,Christie JR.1923. Agamermis decaudata Cobb, Steiner, and Christie: A nema parasite of grasshoppers and other insects. Journal of Agricultural Research.23:921926.

[22] Creighton CS and Fassuliotis, G.1982. Mass rearing of a mermithid nematode, Filipjevimermis leipsandra (Mermithida: Mermithidae) on the banded cucumber beetle (Coleoptera:Chrysomelidae). Journal of Economic Entomology.75:701-703. 
[23] Esaki T and Hashimoto S.1931.Report on the leafhoppers injurious to the rice plant and their natural enemies. Entomological Laboratory, Department of Agriculture, Kyushu Imperial University Publication 2, 54-59.

[24] Fuse H, and Sato M.1968.The parasitism of the Agamermis unka to the rice planthoppers in Yamagata Prefecture. Japanese Journal of Applied Entomology and Zoology.12 (2):97-99.

[25] Greathead DJ.1979. Critical review of natural enemies of insect pests on rice in South and South East Asia and their potential for biological control: proposals for biological studies to assist in development of integrated pests control in rice in South and South East Asia. Commonwealth Institute of Biological Control. Slough, England. pp.126.

[26] Grewal P.S., Ehlers,R. and Shapiro, D.I. (2006) Nematodes as bio control agents Wollingford, UK. CBA international pp 480.

[27] Grigarick A.A. Oraze M.J. 1990. Impact of water management on the effectiveness of nematode applications for control of the rice water weevil p. 72. In: Proceedings, $23^{\text {rd }}$ Rice Technical Working Group 26-28 February 1990 Biloxi, MS Texas A\&M University, College Station, TX.

[28] Heong K.L.(1983) Studies on natural enemies of rice insect Pest. Acta Phytophlacica Sinica, 10:224.

[29] Igbinosa,IB.1988.Parasites of the immature stages of Latoia viridissima Holland (Lep. Limacodidae), a pest of palms in Nigeria. Journal of Applied Entomology.106:527-530.

[30] Imamura S.1932. Mermithidae parasitic on Chilo simplex butler and leafhopper. Oyo-Dobutsugaku Zasshi 4: 176-180.

[31] Israel P, Rao YRVJ, Rao PSP, Varma A.1969. Control of paddy cut worms by DD-136, a parasitic nematode. Current Science 38(16):390-391.

[32] Jayanthi M, Shankar G, Bhaskaran P. 1987.Parasitic nematode in white striated plant hopper (WSPH) of rice. International Rice Research Newsletter.12:23.

[33] Jung YH, Choo HY, Choi JY, Choo YM.2018.Occurence and environmentally friendly control of rice stem borer, Chilo suppressalis in Amur Silver grass (Mischanthus sacchariflorus) plantation. Korean Journal of Pesticide Science.22(1):36-44.

[34] Kaburaki T , Imamura S.1932.Mermithid worm parasitic in leafhoppers, with notes on its life history and habits. Proceedings of Imperial Acadamy.8:139-141.

[35] Kaiser H.1991.Terrestrial and semiterrestrial Mermithidae.pp.899-965.In: WR Nickle.ed. Manual of Agricultural Nematology.New York,Marcel Dekker.

[36] Kamminga KL,Davis JA,Stock SP.,Richter AR. 2012.First report of a mermithid nematode infecting Piezodorus guildinii and Acrosternum hilare (Hemiptera: Pentatomidae) in the United States. Florida Entomologist. 95:214-217.

[37] Karthikeyan K and Jacob.S. 2010. Pseudomonas flourescens and Heterorhabditis indica Poinar for the management of major insect pests of rice. Journal of Biopesticides 3(1): 9699.

[38] Karthikeyan, K. and Jacob, S. 2009. Bioefficacy of white muscardine fungus, Beauveria bassiana (Bals.) Vuill. and entomopathogenic nematode, Heterorhabditis indica (Poinar) against rice blue beetle, Leptispa pygmaea Baly. Journal of Biological Control, 23 (1): 79-81.

[39] Katti, G,Prasad JS, Padmakumari, A. P.Sankar M.2006. Effect of storage periods on survival and infectivity of indigenous entomopathogenic nematodes of insect pests of rice. Nematol.Medit.34: 37-41.

[40] Katti, G., Padmakumari, A. P. and Jonnalagadda, P. S. 2003. An entomopthogenic nematode infecting rice stem borer, Scirpophaga incertulas. Indian Journal of Plant Protection, 32(2): 80-83.

[41] Kega VM, Kasina M, Olubayo F, Nderitu JH. 2020. Effectiveness of entomopathogenic nematodes against the African white rice stem borer Maliarpha separatella Rag. Universal Journal of Agricultural Research 8(2): 41-45.

[42] Kega VM, Kasina M, Olubayo F, Nderitu JH.2013.Management of Maliarpha separatella Rag using effective entomopathogenic nematodes and resistant rice cultivars. Journal of Entomology.10(2): 103-109.

[43] Kisimoto, R., Yamada, Y. and Suzuki. K. 1987. The entomogenous nematode Steinernema feltiae as a biological control agent of the rice water weevil, the brown rice planthopper, and the diamondback moth. In: Recent Advances in Biological Control of Insect Pests by Entomogenous Nematodes in Japan, N. Ishibashi (ed.). Ministry of Education, Culture and Science, Japan, Saga University, Japan, pp. 111115.

[44] Kuno E.1968.Studies on the population dynamics of rice leafhopper in a paddy field.The Bulletin of the Kyushu Agricultural Experiment Station.14(2):131-246.

[45] Li JJ, Qian HT, Dong H, Cong B. 2007. Laboratory test on the infectivity of entomopathogenic nematode to Lissorhoptrus oryzophilus. Chinese Journal of Biological Control 32: 188190.

[46] Manjunath TM.1978. Two nematode parasites of rice brown plant hopper in India. Intern. Rice Res. Newsl. 3:11-12. Hexamermis sp. and Mermis sp. isolated from Nilaparvata lugens.

[47] Meneses CR. 1983. Pathogens and nematodes for control of rice water weevil in Cuba. International Rice Research Newsletter. 8(6):16-17.DD-136

[48] Mikkelsen DS and Datta, SKD.1991.Rice culture .In: Volume Rice Production(BS Luh (ed).pp.103-186.Van Nostrand Reinhold,New York.

[49] Nagata, T. 1987. Infectivity of Steinernema feltiae on the rice water weevil, Lissorhoptrus oryzophilus Kuschel. In: Recent Advances in Biological Control of Insect Pests by Entomogenous Nematodes in Japan, N. Ishibashi (ed.). 
Ministry of Education, Culture and Science, Japan, Saga University, Japan, pp. 65-70.

[50] Nayak P., Rao YRVJ, Yadava CP., Rao YS.1977.Occurrence of a new entomophilic nematode on rice stem borer, Sesamia inferens. Oryza 14:51-54.

[51] Nayak P.,Rao YS.1978. Occurrence of a new entomopathogenic nematode Parasitorhabditis on rice stemborer Sesamia inferens. Oryza J. Asso. Rice Res. Work.14: 51-54.

[52] Nickle,WR.1981.Mermithid parasites of agricultural pest insects. Journal of Nematology.13: 262-266.

[53] Otake A.1979. Natural enemies of the brown planthopper. pp. 42-57. In: Brown Planthopper: Threat to rice production in Asia. International Rice Research Institute, Los Banos, Laguna, Philippines.

[54] Padmakumari AP, Prasad JS, Katti G, Sankar M. 2007. Rhabditis sp (Oscheius sp), a biocontrol agent against rice yellow stem borer, Scirpophaga incertulas. Indian Journal of Plant Protection. 35(2):255-258

[55] Padmakumari, A.P., Katti, G., Sankar, M. and Prasad, J.S.2008. Entomopathogenic nematodes in Rice Pest Management. Technical Bulletin No. 32. Directorate of Rice Research (DRR), Rajendranagar, Hyderabad, A.P., India. 21 P.

[56] Patel CB, Shah AH.1988.Nematodes (Mermithids) as a parasite of larvae of Leptispa pygmaea Baly. Indian Journal of Entomology 14:354.

[57] Pathak, M. D., Khelsa, M. S. and Varma, S. K. 1982. Controlling major pests of rice plant. Indian Farmers Digest, 15 (10): 6-9.

[58] Pena NP, Shephard SM. 1985. Parasitism of nematodes on three species of hopper pests of rice in Laguna, Philippines. International Rice Research Newsletter. 10:19-20.

[59] Peterson,JJ.1984. Nematode parasites of mosquitoes. In: Plant and Insect Nematodes.WR Nickle(Ed.). Marcel Dekker, New York, USA. Pp.797-820.

[60] Poinar GO Jr.,Chang PM.1985.Hexamermis cathetospiculae n.sp. (Mermithidae: Nematoda), a parasite of the rice stemborer, Tryporyza incertulas (Wik.) (Pyralidae: Lepidoptera) in Malaysia. J.Nematol.17:360-363.Scirpophaga incertulas

[61] Prasad JS, Katti G, Padmakumari AP, Sankar M. 2006. Bioefficacy of indigenous entomopathogenic nematodes against leaf folder, Cnaphalocrocos medinalis Guenee in rice.pp.418.In: Proceedings of the $2^{\text {nd }}$ International Congress held on October, 9-13, at National Academy of Agricultural Sciences,New Delhi.

[62] Prasad JS, Katti G, Padmakumari AP,Pasalu IC.2003.Exploitation of indigenous entomopathogenic nematodes against insect pests of rice.pp.121-126. In: Current status of research on entomopathogenic nematodes in India (Hussaini SS, Rabindra RJ, Nagesh M, Eds.). Project Directorate of Biological Control, Bangalore, India.
[63] Prasad JS, Padmakumari AP, Somasekhar N, Katti G. 2016. Entomopathogenic nematodes as a component in rice pest management: A journey from lab to land. In: Plant Health Management for Food Security: Issues and Approaches (Varaprasad KS, Katti G, Kodaru A). Daya Publishing House. New Delhi, 199-212.

[64] Ramakrishnan N.and Kumar, S.1981.Recent advances in insect pathology in India.In: Recent Advances in Entomology in India(ed. Ananthakrishnan TN).Pp.79-97. Madras University Press,Madras.India.

[65] Ramani S. (2003) Biological control of rice insect pests, Biological control of crop pests in India, Kalyani Publisher. pp 349.

[66] Rao, V.P, Basy AN, Phalak VR, Checko MJ, Rao HD.1968.Some new records of parasites of rice stem borer in India .Indian Academy of Sciences, Section B,68:91-110.

[67] Rao, V.P., Manjunath, T.M., 1966. DD-136 nematode that can kill many insect pests. Indian Farming 16, 43-44.

[68] Rao, YRVJ, Prakasa Rao, P. S., Varma, A. and Israel, P. 1971.Tests with an insect parasitic nematode DD-136 (Nematoda: Steinemematidae) against rice stem borer, Tryporyza incertulas Walk. Indian Journal of Entomology, 33: 215 - 217.

[69] Reissig WH, Heinrichs EA,Litsinger JA,Moody K, Fiedler L,Mew TW and Barrion AT.1986.Illustrated guide to integrated pest management in rice in tropical Asia. Intern. Rice Res. Inst. Los Banos, Laguna, Phillippines.

[70] Ring DR, Browning HW. 1990. Evaluation of entomopathogenic nematodes against the Mexican rice borer (Lepidoptera: Pyralidae). Journal of Nematology. 22:420-422.

[71] Rubtsov,IA.1969. On a new species of Agamermis (Mermithidae) of a bug in Poland. Acta Parasitologica Polonica.16:97-99.

[72] Rubtsov,IA.1977. New genus and two new species of mermithids from bugs.Parazitologiia.11:541-544.

[73] Sankar,M, Prasad, J.S., Padmakumari, A.P, Katti G. and Divya K.2009. Combined application of two entomopathogenic nematodes, Heterorhabditis indica and Steinernema asiaticum to control the rice leaf folder, Cnaphalocrosis medinalis (Goen.). Journal of Biopesticides 2(2): 135-140.

[74] Satpathi CR,Sarkar A, Acharjee P.2008. Factors affecting abundance of Hexamermis sp. in rice plant in Eastern India. International Journal of Nematology 18(1): 75-78.

[75] Satpathi CR.1999. Record of nematode (Hexamermis sp.) on brown planthopper in West Bengal. Insect Environment 5:89.

[76] Satpathi CR.2009. Relationship between parasitic nematode, Hexamermis sp. and brown planthopper, Nilaparvata lugens Stal in rice crop in Eastern India. International Journal of Nematology 19(1):120.

[77] Srinivas, P.R. and Prasad, J.S. 1991. Record of DD-136 nematode infection in rice leaf folder (Cnaphalocrocis 
medinalis). Indian Journal of Agricultural Science 16(5): 348349

[78] Sun W,Cong B,Dong H,Qian H.2006. Study on the efficacy of S.feltiae Otio on rice water weevil in laboratory. Journal of Anhui Agricultural Science 34:1620-1621.

[79] Sutanov MA,Artyukhovskii AK,Lysikova EA.1990.Hosts of mermithids-The most important pests of farm and forest plants in Uzbekistan.pp.186-191.In: MD. Sonin and VS Kothekar.eds. Helminths of insects. New Delhi, India, Oxonian Press.

[80] Torii T. 1975. Feasibility of using the entomophilic nematode, DD-136 as a biotic insecticide against rice stem borer,as a biotic insecticide against rice stem borers. In: Approaches in Biological Control.Yasumatsu K.and Mori H.(Eds).pp.8788.University of Tokyo Press, Tokyo.

[81] Vandergast AG,Roderick GK.2003.Mermithid parasitism of Hawaiian Tetragnatha spiders in a fragmented landscape. Journal of Invertebrate Pathology.84:128-136.

[82] Way MO, Bowling CC.1991.Insect pests of rice. In: Volume Rice Production (BS Luh Ed).pp.237-268.Van Nostrand Reinhold, New York.

[83] Yadav CP, Rao YS. 1970. On the effectiveness of entomopathogenic nematode, DD-136 in the biological control of insect pests of rice. Oryza. 7:131-136.

[84] Yan S, Qian H, Xia K, Ling L.1986.Life cycle of Amphimermis sp., a nematode parasite of the brown plant hopper in China. Acta Phytophylacica Sinica 13:79-84.

[85] Zhao HT., Hu Z.L, Zhang S.L1987.Field occurrence of Agamermis sp., a nematode parasite of rice hoppers. Chinese Journal of biological control.3:73-77. 